\title{
我国民生装备优化升级路径及对策研究
}

\author{
古依莎娜 ${ }^{1}$, 吴海华 ${ }^{2}$, 朱晓光 $^{3}$, 杨海鹏 $^{4}$, 秦永清 ${ }^{5}$ \\ （1. 中国工程院战略咨询中心，北京 100088；2. 中国农业机械化科学研究院，北京 100083; \\ 3. 中国轻工业发展研究中心, 北京 100873；4. 中国纺织机械协会, 北京 100028; \\ 5. 中关村医疗器械产业技术创新联盟, 北京 100191)
}

\begin{abstract}
摘要: 民生装备是高端装备的重要组成部分, 在国民经济发展中具有重要地位和作用。我国民生装备的国际竞争力和综合水 平与国际先进水平相比存在一定差距, 新型冠状病毒肺炎疫情的出现进一步暴露出我国食品、纺织、医疗等民生装备发展存 在严重短板, 优化升级的迫切性突出。本文选取农业、食品、纺织、医疗这 4 个涉及国民经济基础命脉的民生装备领域, 研 究相关装备的发展现状并进行国内外比较分析, 指出我国民生装备发展存在的问题及短板。研究提出, 发展民生装备应以智 能制造为主攻方向, 研制具备数字化、网络化、智能化功能的装备, 研发关键零部件、工业软件, 推动民生装备企业实施数 字化、网络化、智能化改造升级并与服务业深度融合。研究建议：国家统筹民生装备领域的扶持政策，开展大规模新一轮技 术改造, 建设行业技术创新服务公共平台, 加强国产装备和工业软件的研发与应用, 由此保障和推动民生装备的优化升级。 关键词: 民生装备；智能制造；优化升级；农业；食品；纺织；医疗
\end{abstract}

中图分类号：F424 文献标识码：A

\section{Path and Countermeasures of Optimizing and Upgrading Livelihood Equipment in China}

\author{
Gu Yishana ${ }^{1}$, Wu Haihua ${ }^{2}$, Zhu Xiaoguang ${ }^{3}$, Yang Haipeng ${ }^{4}$, Qin Yongqing ${ }^{5}$ \\ (1. Center for Strategic Studies, Chinese Academy of Engineering, Beijing 100088, China; 2. Chinese Academy of \\ Agricultural Mechanization Sciences, Beijing 100083, China; 3. China Light Industry Development Research \\ Center, Beijing 100873, China; 4. China Textile Machinery Association, Beijing 100028, China;
}

5. Zhongguancun Medical Innovation Alliance, Beijing 100191, China)

\begin{abstract}
Livelihood equipment is an important part of high-end equipment. It plays an important role in the development of national economy. China's livelihood equipment lags behind the international advanced level in terms of international competitiveness and comprehensive level. The outbreak of the coronavirus disease 2019 (COVID-19) further exposed the serious shortcomings in China's livelihood equipment concerning medical treatment, food, textile, and the like, as well as the urgent need for optimization and upgrading of the industry. In this paper, livelihood equipment regarding agriculture, food, textile, and medical treatment are studied, which are related to the lifeblood of the national economy. Their development status is reviewed, and the problems and shortcomings of China's livelihood equipment are proposed. The research suggests that intelligent manufacturing should be the major development direction of the livelihood equipment. Specifically, equipment with digital, networked, and intelligent functions should be developed; key components and industrial software should be researched; digital, networked, and intelligent transformation and upgrading of livelihood equipment enterprises should be promoted; and integration with the service industry should be deepened. To ensure and
\end{abstract}

收稿日期 : 2020-01-19; 修回日期 : 2020-03-03

通讯作者：古依莎娜, 中国工程院战略咨询中心高级工程师, 研究方向为制造业发展战略; E-mail: gysn@cae.cn

资助项目：中国工程院咨询项目 “新兴产业发展战略研究（2035）”(2018-ZD-12)

本刊网址：www.engineering.org.cn/ch/journal/sscae 
promote the optimization and upgrading of the livelihood equipment in China, the state should make overall plans for supporting policies regarding the livelihood equipment, conduct large-scale technological transformation, build a public platform for technological innovation services for the industry, and strengthen the development and application of domestic equipment and industrial software.

Keywords: livelihood equipment; intelligent manufacturing; optimize and upgrade; agriculture; food; textile; medical treatment

\section{一、前言}

民生产业即直接关系人民生活的相关产业，如 农业、食品安全、纺织、医疗卫生、家电、家具等, 在吸纳就业、满足人民日益增长的消费需求等方面 发挥着重要作用, 同时也是我国出口创汇的重要产 业, 在国民经济结构中占有重要地位。民生产业是 国家经济发展的 “刚需”, 在国家面对重大突发应 急事件如新型冠状病毒肺炎（COVID-19）疫情时, 强大的民生产业可以助力国家快速走出困境, 为经 济社会的高质量发展奠定重要基础。

民生装备作为服务于民生产业的装备, 是国 家高端装备体系的重要组成部分。在我国消费升 级空间拓展和传统制造业升级换代过程中，民生 装备的发展壮大始终是关键 “落脚点”。以民生装 备的优化升级为着力点, 践行制造业高质量发展 路径, 对推动制造强国战略目标的实现具有重大 现实意义。

当前, 社会上存在着民生产业是夕阳产业、民 生装备是低端装备的错误观点, 如不及时纠正, 将 会妨碍国家产业体系的健康发展, 影响对重大突发 应急事件的有效应对。因此, 开展我国民生产业和 民生装备的发展战略研究, 有利于厘清产业发展现 状, 明晰装备发展路径, 促进全社会对民生装备发 展的合理重视。农业、食品、纺织、医疗是 4 个涉 及国民经济基础命脉的重要领域, 相关装备与国民 的吃、穿、用及健康密切相关, 对这些领域开展装 备优化升级研究意义重大。

\section{二、民生装备产业发展地位判断}

\section{（一）民生产业发展的重要基础}

民生产业为我国的消费升级提供了坚强保障。 民生装备服务于民生产业, 是民生产业发展的重要 基础。我国改革开放 40 多年来, 民生装备助力民 生产业取得了显著进步。
以纺织装备为例, 经过多年的发展, 在研发、 创新、技术运用以及人性化设计方面有了大幅提 高, 在高端纺织装备、优质专用基础件、高性能纤 维成套技术工艺装备等方面取得了良好的成果。纺 织装备的快速发展促进了纺织产业的进步。在改革 开放初期, 我国居民服饰还是一片 “黑、灰、蓝”, 1983 年才取消布票。而如今, 我国年人均纤维消 费量超过 $20 \mathrm{~kg}$, 达到中等发达国家水平 [1]。根据 国家统计局数据测算, 2018 年我国化纤产量约为 $5.011 \times 10^{7} \mathrm{t}$, 占世界总产量的 $80 \%$ 以上 [2]。我国 印染行业的生产规模位居世界第一，印染纺织品产 量占全球总产量的 $60 \%$ [3]。纺织装备的发展, 为 纺织产业提供了丰富的功能应用, 为各类纺织品和 服装的发展提供了更大的空间, 促进了产品竞争力 的提升。

\section{（二）高端装备的重要组成部分}

高端装备是指技术含量高, 具有高附加值, 占 据产业链核心地位的装备。随着民生产业对产品多 样性、材料使用以及安全性的要求越来越高, 民生 产业对核心关键装备的性能要求也随之提高。尤其 是在新一轮科技革命的推动下, 民生装备朝着数字 化、网络化和智能化的方向发展, 逐渐成为高端装 备的重要组成部分。

在医疗装备中, 高端装备将医学与新一代信息 技术、先进制造技术深度融合, 技术含量大幅提升, 如高端医学影像设备的 $3 \mathrm{~T}$ 超导磁共振、128 排电 子计算机断层扫描 ( $\mathrm{CT}$ 机)、正电子发射计算机 断层显像 (PET-CT 机)、196 通道高端彩超、数字 减影血管造影（DSA）、超声内镜等。在食品装备 中, 采用了高效无焦结热交换、电磁加热 / 超声辅 助/电子束 / 脉冲强光新型物理杀菌、热敏物料在 线过滤除菌、高速无菌灌装、无死角在线清洗 / 在 线灭菌 (CIP/SIP)、设备整机无菌验证等关键技术, 研发了高端食品无菌高速灌装设备、超薄金属罐高 速封口装备、高压均质粉碎装备、超高压食品加 
工处理装备、全谷物加工技术及装备等。农业装备 中的 “耕种管收” 田间作业装备逐步实现了无人驾 驶、自动操作、自动监控等功能, 并朝着大型高效、 精巧灵活、多功能、智能化方向发展; 农产品加 工与储运、设施园艺与养殖装备等朝着成套化、 绿色化、信息化、智能化方向发展。在纺织装备中, 纺纱、织造、印染、化纤加工等装备品种繁多且 造型多变。

\section{（三）发达国家产业升级的发展方向}

世界主要发达国家在民生装备方面普遍加大 科研投入, 且高度重视装备的专利知识产权。以 食品装备为例，科研投入资金约占企业营业额的 $8 \% \sim 12 \%$, 且呈逐年增长态势 [4]。世界主要发达国 家在民生装备方面的发展表达如下。

美国在农业装备领域一直保持世界领先水平, 重视农业资源高效利用以及可持续发展所需装备的 研制和使用。龙头机械企业为农业提供了大量机械、 化肥、飞机等先进生产装备, 促进了农业生产力的 跨越式发展, 并使农业成为重要出口产业。

德国将纺织业转型升级提升到国家战略高度, 将其列为工业 4.0 发展的重要领域。在 “未来纺织” 项目中, 未来纺织品工厂、数字化制造过程、柔性 生产装备、精密纺织设备和先进缝㧅设备等被列为 重点发展方向。

另外, 主要发达国家将大数据、物联网、人工 智能 (AI) 等新一代信息技术应用到民生装备的不 同场景中。如美国正在研究把卫星通信、遥感技术、 $\mathrm{AI}$ 等技术推广应用到农业装备上以提高农业生产效 率。国外主要纺纱装备企业推出单锭监测及粗纱停 喂系统, 运用大数据集中采集和分析处理, 实现了 纺纱厂的夜间无人值守。

\section{（四）突发应急事件的重要保障}

民生装备是防范和应对突发事件的基础性物质 保障。在应对重大突发事件时, 民生装备的先进性、 可靠性以及民生产业链的韧性和弹性, 切实保证人 民群众基本生活用品需要, 成为提升全社会应急救 援能力和风险抵御水平、保障人民群众生命财产安 全、维护国家公共安全的重要民生基础。

以我国应对 COVID-19 疫情为例, 在疫情初期, 一些医疗物资严重缺乏从而加剧了医疗系统应对疫
情的困难; 但在很短时间内, 医疗装备产业领域尽 快进行了调整, 全力生产口罩、防护服、检测试剂、 呼吸机、人工心肺机等医疗装备, 为大量医护人员 驰援武汉抗击疫情提供了坚实的物质基础。如检测 试剂的检测结果时间由 2 3 d 提升至 $30 \mathrm{~min}$; 多家 国产 $\mathrm{CT}$ 机迅速在火神山医院、雷神山医院、方舱 医院安装运行; 无论在质量上还是数量上, 呼吸机 全面满足了临床应用需求, 同时还向有需要的国家 出口。

纺织装备在病毒防控、洪水防治、抗震救灾、 火场救援等各类重大应急事件中发挥着特有的支撑 和保障作用。在医用方面, 纺织装备为口罩、医用 防护服的生产提供了基础支撑, 是缓解疫情防控物 资紧缺的重要保障; 在基础设施建设方面, 纺织装 备为在防汛抢险中发挥重要作用的土工布提供生产 支持; 在地震、火灾等各类灾害的救援方面, 纺织 装备用于大量提供帐篷、救援和逃生绳（索）具、 特种防护服装等产业用纺织品。

\section{三、民生装备产业发展现状分析}

\section{（一）纺织装备走在世界前列}

我国纺织装备门类齐全, 纺织产业链完整。纺 织机械产品销售额占到全球的 50\% 左右, 国产纺 织装备的国内市场占有率达到 $80 \%$, 高端装备关键 基础件的国产化率超过 50\%。自 2015 年起, 我国 纺织机械的出口额超过进口额, 且出口额排名位居 世界前列 [5]。一批中型规模的纺机企业在纺纱机 械、印染机械等细分领域达到了国际先进水平。另 外, 我国在成规模应用机器人作业的生产线自动化、 智能化推进方面已走在世界前列。

\section{（二）食品装备存在较大差距}

在全球食品装备产业中, 欧洲、美国、日本等 国家或地区占据领先地位。德国食品装备工艺流程 自动化程度最高, 创新能力全球领先, 占据了欧洲 食品装备市场的 70\%、世界食品装备出口市场的 $30 \%$ 。美国的食品装备具有高度信息化特征, 普遍 实现了机电一体化控制。日本的食品装备以中小型 单机为主, 具有体积小、精度高、易安装、操作方 便、自动化程度高等特点 [6]。

我国食品装备能够基本满足国内食品工业生产 
需求, 但进出口贸易逆差较大的状况尚未得到根本 改变, 技术水平与国际先进水平相比存在较大差距。 具体表现为: 食品装备自动化程度低, 单机产品多、 成套设备少; 高技术、高附加值产品少; 初加工设 备多, 深加工设备少; 通用机型多, 特殊要求、特 殊物料加工机型少。

\section{（三）医疗装备存在较大差距}

2018 年全球医疗装备市场份额约为 4428 亿美元, 其中美国约为 1479 亿美元 [7]; 我国约为 700 亿美元, 约占全球市场总份额的 1/7 [8]。国产医疗装备与国 际先进水平存在较大差距, 在高性能医疗器械方面 对外依赖度高, 如国内县级以上医院配置的医学影 像设备, 国外品牌仍占主导地位。但近几年我国逐 步研发了一批达到或接近世界先进水平的高性能医 疗装备, 如超声设备和全自动生化设备、 $\mathrm{CT}$ 机、 超导磁共振等高端医学影像设备、脑起搏器等, 初 步具有了在国内市场上与国外产品展开正面竞争的 能力。部分国产设备如全自动生化仪、超声诊断、 脑起搏器、冠脉血管支架已在国内市场具有较强的 竞争优势, 并可替代进口。整体来看, 我国医疗器 械产业可以满足国内医疗的基础需求, 但在高性能 医疗装备方面仍有较大提升空间。

\section{（四）农业装备存在巨大差距}

我国是农业装备制造和使用大国, 但不是强国, 在产业总体水平、技术产品创新能力以及企业国际 市场竞争力方面与美国、德国等领先国家存在着 巨大差距 [9]。从农业装备的规模上看, 2018 年我 国农业装备企业总数超过 8000 家, 其中规模以上 企业超过 2300 家, 产业规模约占全球的 30\% [10], 但产品增加值率和利润率仅为国际领先水平的 $1 / 10$ 。从农业装备的技术水平来看, 我国农业装备 技术性能及可靠性尚未达到国外领先水平, 在核心 技术、高性能零部件、重大装备供给及自主创新等 方面存在短板, 与全程、全面、高质、高效农业机 械化和农业高质量发展需求不相适应。

\section{四、民生装备产业发展存在的问题}

从现状分析来看, 我国民生装备的国际竞争力 和综合水平与发达国家相比存在较大差距, 尤其是
在应对突发应急事件时, 民生装备的发展暴露出一 些短板。关键技术和零部件受制于人, 产品质量和 可靠度亟待提高, 原始创新及研发投入不足等问题 依然是民生装备发展的 “绊脚石”, 严重影响了我 国民生装备的优化升级。

\section{（一）关键技术和零部件受制于人，严重依赖进口}

(1) 在农业装备方面, $200 \mathrm{hp}$ 以上拖拉机、大 型谷物收割机、6 行采棉机、甘蔗联合收获机械等 高端产品进口比重仍旧较大, 电液控制系统、打 捆机打结器、采棉机采棉指等关键零部件主要依 赖进口。

（2）在食品装备方面, 关键原材料、关键零配 件、高精度伺服系统等依赖进口, 食品安全技术装 备精度和稳定性较国际先进水平差距较大, 实验室 用高端精密检测仪器需从国外进口。

（3）在纺织装备方面, 核心零部件、装备集 成、信息化管理软件等尚未完全掌握核心技术, 关 键功能部件依赖进口。自 COVID-19 疫情暴发以来, 全国甚至全球对口罩和防护服生产设备的需求量剧 增, 作为防护原料的熔喷非织造布也极其紧缺; 但 我国纺织装备中的熔喷非织造布成套设备的速度、 单线产能以及核心零部件（如熔喷模头）与国外发 达国家的先进水平相比还有一定差距。

（4）在医疗装备方面, 超导磁体、CT 球管、 换能器、探测器、光学部件、血管支架、骨关节 器件等关键部件严重依赖进口。在 COVID-19 疫 情期间, 医疗工作对医用服务机器人、AI 咨询服 务系统、 $\mathrm{AI}$ 辅助 $\mathrm{CT}$ 影像智能诊断系统都提出了 迫切的需求。

\section{（二）产品质量和可靠度亟待提高}

我国农业装备质量水平普遍不高, 农机产品可 靠性指标仅为国外的 50\% 左右，作业效率、水肥 种药利用率仅为国外的 $70 \%$ 左右, 能耗水平高于 国外先进水平 $30 \%$ 以上，生产过程损失率高于国 外先进水平 $20 \%$ 左右 [11]。

在纺织装备方面, 机械制造工业技术和生产方 式成为当前发展的瓶颈。由于国产纺织装备制造、 装配、热处理及表面处理等工艺技术及质量管理水 平相对不高, 导致装备运行稳定性欠佳; 部分零配 件质量较差, 降低了国产主机的使用可靠性。食品 
装备的性能与国外同类产品相比, 生产能力低、能 耗高, 且大型成套设备方面的性能差距更大。

\section{（三）原始创新不足, 以引进消化吸收为主}

我国民生装备自主创新及集成创新能力不足, 对基础研究和共性关键技术研究重视程度不够, 对 国外先进技术依赖度高, 直接影响了行业整体技术 水平的提升。具体来看, 缺乏装备专用先进设计技 术及平台, 缺少运用建模 / 仿真技术开发系统化成 套化技术装备以及高效可靠智能装备的能力, 整线 工艺设计集成水平的差距较大。

\section{（四）研发投入严重不足}

我国民生装备的研发投入偏低, 技术体系不完 整, 制约了民生装备的发展。在农业装备方面, 企 业规模小、研发投入少, 仅有不到 $5 \%$ 的农机企 业建立了研发部门, 不到 $1 \%$ 的农机企业建立了较 为完善的企业技术体系, 企业研发投入比例不足 $2 \%$ [12]。在食品装备方面, 国外企业的发展经验表 明, 研发投入占比达到 $5 \%$ 时才会形成明显的竞争 力; 而我国企业研发投入的占比平均不足 $1 \%$, 全 国研发经费只占企业销售收入的 $0.3 \% \sim 0.4 \%$, 研发 人员数量仅占从业人员的 $3.4 \% \sim 4 \%[12]$ 。

\section{五、民生装备产业优化升级发展路径}

当前, $\mathrm{AI}$ 技术与先进制造技术融合形成的新 一代智能制造技术, 成为新一轮工业革命的核心驱 动力。新一代智能制造引发制造业发展理念、制造 模式发生重大而深刻的变革, 将重塑制造业的技术 体系、生产模式、发展要素及价值链。从应对公共 卫生或自然灾害等突发事件的经验来看, 加快关键 核心技术攻关, 提高装备智能化水平, 实现装备自 主可控是当前民生装备发展的重要任务。要以智能 制造为主攻方向, 扎实推进民生装备优化升级和中 高端发展。

\section{（一）重点研制具备数字化、网络化、智能化功能 的装备, 提升装备质量和附加值}

支持企业加大对新装备的研发投入, 研制生产 科技含量高的装备、满足重大突发应急事件及市场
消费升级所需的高端装备以及新兴产业所需的跨领 域装备, 逐步将我国民生装备的规模（量）优势转 化为价值 (质) 优势。

（1）在农业装备方面，重点发展 “耕种管收” 智能作业装备、智能养殖装备与设施、农产品加工 智能装备与设施等。推进物联网、大数据、互联网、 第五代移动通信 (5G) 技术在农业生产和农机作业 中的应用, 发展新一代智能农业装备, 实现农业装 备智能作业、远程运维管理。

（2）在食品装备方面, 补齐我国高端食品装备 短板, 发展以智能机器人为核心的无人化服务, 以 及零接触、零交叉感染、高可靠性、 $24 \mathrm{~h}$ 在线的智 能化、数字化、自动化整线。

（3）在纺织装备方面, 重点研制智能化连续纺 纱生产装备、数控机织装备、数控非织造布生产装 备、智能化针织装备、智能化服装生产线等。在熔 喷非织造布成套设备的智能管理、状态数字化监控、 信息全流程追溯分析、智能分切等方面着力开展进 一步技术攻关。

（4）在医疗装备方面, 重点开发智能化医用服 务机器人、 $\mathrm{AI}$ 咨询服务系统、基于大数据的 $\mathrm{AI}$ 辅 助 CT 影像、智能诊断系统、医学增材制造设备、 数字化医疗影像设备、虚拟现实手术模拟等医疗新 技术产品。

\section{（二）推动民生装备企业的改造升级}

根据各地区以及相关企业的实际情况, 推动开 展数字化、网络化、智能化改造, 重塑民生装备产 业的技术体系、生产模式和价值链。

在改造升级过程中, 相关企业要优先打好质 量管控、精益生产、工艺优化、数据积累等方面 的基础, 做好适应性方案设计, 从生产单元的数 字化和智能化入手, 逐步建设数字化生产线、数 字化车间和数字化工厂。

\section{（三）推动民生装备与服务业深度融合}

通过跨域融合积极开拓新领域, 从以产品为中 心向以用户为中心转变, 发展规模化定制生产、云 平台、共享制造、远程运维等新模式和新业态。通 过大数据应用和柔性化生产线建设, 开展系统和管 理组织创新, 将企业之间的成本竞争转向满足用户 
个性化需求的服务竞争。

积极探索平台经济发展, 支持民生装备企业 构建或者参与平台模式来获得更多的发展机会。支 持民生装备企业构建以客户为中心的生产和管理模 式, 实现企业的组织重构、生产流程再造、商业模 式创新、新产品设计制造等。例如, 在医疗装备方 面, 重点推进基于 $5 \mathrm{G}$ 的健康大数据、 $\mathrm{AI}$ 诊断系统、 设备运行质量保障与临床大数据融合等系统的开发 与平台建设, 推进康复与保健装备的智能化技术、 人体功能辅助设备及训练设备等的研发。

\section{（四）研发关键零部件和工业软件}

围绕智能制造亟需, 突破关键零部件、工业软 件等产业基础薄弱环节, 推进智能关键零部件与工 业软件的自主研发与产业化，提升民生产业链的㓞 性水平和安全性。

（1）在农业装备方面, 加强对土壤、动植物、 环境感知、调控基础理论以及关键共性技术的研究, 提升控制系统的能力和水平; 研究动植物生理、生 长、环境信息感知的相关技术、材料和元器件; 研 究种、水、肥、药、光、热等精准精量调控及精细 饲喂技术及系统; 研究构建动植物全生命周期智能 调控技术体系，推动实现农业生产由群体向个体、 由总量调控向变量调控的智能精细生产的转变。

（2）在食品装备方面, 重点发展食物直接接触 材料和可循环利用包装材料, 如高性能聚合物空心 膜、食品级特种钢材、橡胶材料、特种塑料等; 重 点发展基于可编程逻辑控制器（PLC）、料（液）位 传感器、微型流量传感器的控制系统, 超高压阀门 及筒体, 高效伺服机, 减速机, 封盖机以及相关工 业软件。

(3) 在纺织装备方面, 优先发展纺织新材料和 高端纺织品的关键技术部件, 如应用于应急与公共 安全、基础设施建设工程、海洋工程、健康工程等 领域的关键部件; 重点研发高性能纤维应用产品、 生产装备及操作系统和工业软件，如 T1200、M60J 等高规格碳纤维产品, 强度 $40 \mathrm{cN} / \mathrm{dtex}$ 以上的高强 高模聚乙烯产品，K129、K149、KM-2 等高规格芳 纶等。

（4）在医疗装备方面, 针对医学影像、临床 检验、先进治疗等设备, 加强关键核心部件、元 器件、软件系统等的基础研究; 针对生物医用材
料产品, 加强基础材料、工艺、加工设备及软件 的应用开发。

\section{六、对策建议}

\section{（一）统筹民生装备领域的发展扶持政策}

近年来，国家不断加大对民生装备领域的政策 支持力度, 产业进展良好。但与国际先进水平相比, 相关领域的科技含量、关键技术和装备研发水平仍 有较大的发展空间, 精准化的政策引导与扶持力度 有所不足。建议对分散于农业、食品、纺织、医疗 等民生装备领域的产业发展政策进行统筹, 突出共 性发展亟需，体现个性发展特征，优化形成民生装 备领域的政策体系; 重点鼓励技术创新和研发性生 产, 加快推进民生装备领域新材料、高端元器件、 先进制造等高端技术的跨行业、跨部门产业应用和 融合发展。

\section{（二）开展较大规模的新一轮技术改造}

技术改造是产业升级的直接且必要途径, 农 业、食品、纺织、医疗等民生装备领域 “面宽量大”, 实施技术改造具有突出的潜能。梳理和总结原有的 分散于各个层级的技术改造经验和得失, 为新一轮 技术改造找准方向和重点。在新一轮技术改造的实 施过程中，优化各级政策导向、提供必要的资源支 持，综合发挥好政府和市场的各自作用。同时，兼 顾技术改造资金的效率和规模，各级财政设立技术 改造专项资金, 将民生装备类的企业改造升级列为 重点。鼓励相关企业增加技术改造投资，找准市场 回报和收益预期良好的方向，注重提高装备技术的 自主可控程度, 切实保障企业工艺装备升级和核心 竞争力提升。

\section{（三）建立行业技术创新服务公共平台}

从突出重点、提高效率、保障覆盖的角度看, 建议集中力量, 重点开展民生装备领域技术创新服 务公共平台的建设，协调整合行业科技资源，突破 产业共性关键技术和大型装备核心技术, 实现 “产 学研” 技术创新的良性互动。建设民生装备行业质 量监督检验和标准化工作平台，支持行业信息服务 平台建设, 解决民生装备行业当前跨部门技术封闭、 研发投入重复、产业化应用因难等问题；建立适应 
民生装备标准化发展的运行机制, 形成以企业为主 体、“产学研用” 相结合、中介服务为桥梁的标准 研制体系，构建面向市场、重点突出、结构合理的 技术标准体系。

\section{（四）加强国产装备和工业软件的研发与应用} 建议相关政策予以适度倾斜，推动国产民生装 备、关键零部件和工业软件的研发和应用。制定鼓 励农业、食品加工、纺织服装企业和健康医疗服务 机构应用国产民生装备的政策体系，促进民生装备 在实际应用过程中的迭代创新；根据用户需求不断 研发新产品, 提高技术水平、产品质量和可靠性。 推进我国民生产业建设自主可控的产业链, 培养系 统集成企业队伍，形成民生产业产品和服务不断创 新、民生装备不断优化升级的具有良性循环功能的 产业体系，支撑我国民生产业的健康有序发展。

\section{参考文献}

[1] 许欢. 挖掘国内消费市场潜力一一中纺圆桌论坛第十四届年会 在北京召开 [J]. 中国纤检, 2019 (2): 107-108.

$\mathrm{Xu} \mathrm{H}$. Tap the potential of the domestic consumer market: The 14th China textile round-table forum annual conference held in Beijing [J]. China Fiber Inspection, 2019 (2): 107-108.

[2] 肖英芝. 2018年我国化纤产量突破50 000 kt [J]. 合成纤维工业, 2019, 42(4): 5.

Xiao Y Z. China's chemical fiber output exceeded $50000 \mathrm{kt}$ in 2018 [J]. China Synthetic Fiber Industry, 2019, 42(4): 5.

[3] 张力. 我国染料业应向环保方向发展 [J]. 纺织服装周刊, 2005 (42): 16 .

Zhang L. China's dye industry should develop in the direction of environmental protection [J]. Textile Information Weekly, 2005 (42): 16 .

[4] 戴相朝, 王国扣. 食品装备国内外科技水平总体分析 [J]. 食品 工业, 2015, 36(8): 248-250

Dai X C, Wang G K. Overall technological level analysis of domestic and foreign food equipment $[\mathrm{J}]$. The Food Industry, 2015, 36(8): 248-250

[5] 墨影. 破局, 突围 中国纺织工程学会第八届纺机器材专业委员
会第一次会议侧记 [J]. 纺织机械, 2016 (9): 20-21.

Mo Y. Break the game and break through: Sidelights of the first meeting of the Eighth Textile Machinery Committee of China Textile Engineering Society [J]. Textile Machinery, 2016 (9): $20-21$.

[6] 郭洪金金. 我国食品和包装机械行业发展趋势 [J]. 机械工程师, 2018 (2): 3-7.

Guo H X. The development trend of China's food and packaging machinery industry [J]. Mechanical Engineer, 2018 (2): 3-7.

[7] 火石创造. 全球医疗器械市场保持高速增长 [N/OL]. 中国 医药报, 2019-09-24(7) [2020-01-10]. http://bk.cnpharm.com/ zgyyb/2019/09/24/222803.html.

Hsmap. Global medical device market keeps rapid growth [N/OL]. China Pharmaceutical News, 2019-09-24(7) [2020-01-10]. http:// bk.cnpharm.com/zgyyb/2019/09/24/222803.html.

[8] 中国药品监督管理研究会. 医疗器械蓝皮书: 中国医疗器械行 业发展报告(2019) [R]. 北京: 社会科学文献出版社, 2019.

China Society for Drug Regulation. Blue book of medical device industry: Annual report on the development of medical device industry in China (2019) [R]. Beijing: Social Sciences Academic Press (CHINA), 2019.

[9] 陈志, 罗锡文, 王锋德, 等. 从零基础到农机大国的发展之 路一一中国农机工业百年发展历程回顾 [J]. 农学学报, 2018, 8(1): 158-162.

Chen Z, Luo X W, Wang F D, et al. Road of development from zero base to a large agricultural machinery country: A review of China agricultural machinery industry in a century [J]. Journal of Agriculture, 2018, 8(1): 158-162.

[10] 王博, 方宪法, 吴海华. 新中国农业装备科技创新的回顾与展望 [J]. 农机质量与监督, 2019 (10): 12-14.

Wang B, Fang X F, Wu H H. Review and prospect of agricultural machinery science and technology innovation in China $[\mathrm{J}]$. Agricultural Machinery Quality \& Supervision, 2019 (10): 12-14.

[11] 贾敬敦, 胡小鹿, 柏雨岑, 等. 国家农业机械产业创新发展报告 (2017) [M]. 北京: 中国农业出版社, 2018.

Jia J D, Hu X L, Bai Y C, et al. Report on the innovation development of China agricultural machinery industry (2017) [M]. Beijing: China Agriculture Press Co., Ltd., 2018.

[12] 吴海华, 方宪法, 杨炳南. 我国农业装备产业技术创新支撑体系 分析 [J]. 农业工程, 2016, 6(4): 1-5.

Wu H H, Fang X F, Yang B N. Analysis of agricultural machinery industry technological innovation support system in China [J]. Agricultural Engineering, 2016, 6(4): 1-5. 